\title{
Solid-contact Potentiometric Sensor for the Determination of Total Ammonia Nitrogen in Seawater
}

\author{
Lan Ding ${ }^{1,2, \dagger}$, Jiawang Ding ${ }^{2, \dagger}$, Baojun Ding ${ }^{1, *}$, Wei Qin ${ }^{2, *}$ \\ ${ }^{1}$ School of Chemistry, Dalian University of Technology, Dalian, Liaoning 116024, P.R. China. \\ ${ }^{2}$ Key Laboratory of Coastal Environmental Processes and Ecological Remediation, Yantai Institute of \\ Coastal Zone Research (YIC), Chinese Academy of Sciences (CAS), Shandong Provincial Key \\ Laboratory of Coastal Environmental Processes, YICCAS, Yantai, Shandong 264003, P.R. China. \\ $\dagger$ The two authors contributed equally to this work \\ *E-mail: dingbj@dlut.edu.cn (B.J. Ding); wqin@ yic.ac.cn (W. Qin)
}

doi: $10.20964 / 2017.04 .01$

Received: 3 January 2017 / Accepted: 4 February 2017 / Published: 12 March 2017

\begin{abstract}
A solid-contact potentiometric sensor for in situ detection of total ammonia nitrogen (TAN, free ammonia plus the ammonium ion) in seawater is described. In the compact system, an all-solid-state polymeric membrane ammonium-seletive electrode is integrated with a polyvinyl alcohol hydrogel buffer film of $\mathrm{pH} 7.0$ and a gas-permeable membrane. The gaseous $\mathrm{NH}_{3}$ in seawater diffuses through the gas-permeable membrane and is converted to $\mathrm{NH}_{4}{ }^{+}$in the hydrogel buffer, which can be potentiometrically sensed by the solid-contact ammonium-sensitive membrane electrode. The electrode configuration facilitates the alteration of $\mathrm{NH}_{3}$ to $\mathrm{NH}_{4}{ }^{+}$in the hydrogel buffer film and improves the sensitivity for the detection of TAN by the buffer trap effect. The gas-permeable membrane effectively eliminates the ion interferences from the seawater sample matrixes. The proposed sensor shows a stable potentiometric response in the concentration range of $10^{-6}-10^{-4} \mathrm{M}$ with a detection limit of $6.4 \times 10^{-7} \mathrm{M}$, and has been successfully applied to the detection of TAN in seawater.
\end{abstract}

Keywords: Ammonia, Hydrogel, Gas permeable membrane, Solid-contact ion-selective electrode, Seawater

\section{FULL TEXT}

(C) 2017 The Authors. Published by ESG (www.electrochemsci.org). This article is an open access article distributed under the terms and conditions of the Creative Commons Attribution license (http://creativecommons.org/licenses/by/4.0/). 